\title{
La sanción en los supuestos de abuso o simulación como un caso de compliance regulado en materia administrativa*
}

\author{
María Pilar Navarro Schiappacasse**
}

\section{RESUMEN}

La Ley $N^{\circ}$ 20.780, siguiendo los postulados de la OCDE, introdujo en la legislación tributaria un ilícito de carácter administrativo que sanciona al asesor tributario que ha diseñado o planificado actos, contratos o negocios constitutivos de abuso o simulación. Su estructura dogmática recoge las normas del compliance penal, pues en el caso de infracciones atribuibles a las personas jurídicas, la sanción se aplicará si los directores o representantes legales han incumplido sus deberes de dirección o supervisión.

Elusión tributaria - sanción administrativa - compliance penal

\section{A case of compliance regulated in administrative matter: the Chilean sanction to the tax advisor in cases of abuse or sham}

\begin{abstract}
The 20.780 Act, following the OECD's requirements, introduced into the tax's law an administrative illicit that fines to the tax advisor who has designed or planned acts, contracts or arrangements which are constitutive of abuse or sham. Its dogmatic structure references to the criminal compliance. Thus, in the case of the infringements attributable to legal entities, the sanction will apply to the directors and legal representatives who have failed to comply its direction and supervision obligations.
\end{abstract}

Tax avoidance - administrative sanction - criminal compliance

* Este trabajo corresponde, con ciertos cambios, a una parte de la tesis doctoral "Normas generales antielusión: naturaleza jurídica y sanción”, dirigida por el Dr. Luis M. Alonso González.

** Licenciada en Ciencias Jurídicas, Pontificia Universidad Católica de Valparaíso. Abogada. Doctora en Derecho, Universidad de Barcelona, España. Investigadora postdoctoral, Instituto de Ciencias Sociales de la Universidad de O’Higgins, Chile. 


\section{INTRODUCCIÓN}

$\mathrm{L}$ a Ley $\mathrm{N}^{\mathrm{0}} 20.780$, de 2014, estableció por primera vez en el ordenamiento tributario chileno una norma general antielusión que permite perseguir la correcta tributación de actos y contratos que dan lugar a una planificación tributaria que verifica los presupuestos aplicativos del abuso de las formas jurídicas regulado en el artículo $4^{\circ}$ ter del Código Tributario. Asimismo, de manera expresa se regula la figura de la simulación para los efectos de la correcta determinación de la obligación tributaria en el artículo $4^{\circ}$ quater del mismo Código.

Sin embargo, el estatuto aplicable a ambas figuras no se agota con su mera consagración legal, pues el legislador ha contemplado un conjunto de normas que las complementan, entre estas se encuentra el artículo 100 bis del referido Código, que contempla un ilícito administrativo aplicable al asesor tributario que diseñe o planifique actos o contratos que sean posteriormente declarados abusivos o simulados por un tribunal.

La reforma tributaria impulsada por el gobierno, presentada al Parlamento el 23 de agosto de 2018, Boletín No 12.043-05, que se encuentra en la Comisión de Hacienda de la Cámara de Diputados, en primer trámite constitucional, no efectúa grandes modificaciones a la configuración dogmática del referido ilícito administrativo. De ahí que sea oportunidad para realizar un estudio a este injusto.

Para estos efectos, el examen se dividirá en tres partes: en la primera se revisarán los antecedentes de la incorporación de este ilícito administrativo en la legislación chilena; en la segunda, se analizará la configuración legal del abuso y la simulación, precisando los alcances de cada una y, en tercer lugar, se identificarán sus principales aspectos dogmáticos y las consecuencias que se derivan de la estructura de compliance que presenta. Finalmente, se hará mención de las principales conclusiones a las que se arribó.

\section{Antecedentes}

La Ley N $\mathrm{N}^{\circ}$ 20.780, al incorporar al Código Tributario el abuso de las formas jurídicas y la simulación, consideró la necesidad de incluir una sanción -establecida en el artículo 100 bis del Código Tributario- aplicable a quien hubiera diseñado o planificado las conductas que finalmente sean calificadas por un tribunal como abusivas o simuladas, esto es, como constitutivas de elusión en los (criticables) términos establecidos por el ordenamiento tributario chileno ${ }^{1}$. Para el legislador chileno no era suficiente con privar de los efectos tributarios a la planificación desarrollada por el contribuyente, sino que además se debía endurecer la reacción con el fin de disuadir este tipo de conductas elusivas.

${ }^{1}$ Véanse los artículos $4^{\circ}$ bis y $4^{\circ}$ quater del Código Tributario que hacen mención expresa a que la simulación es un caso de elusión. 
Este ilícito constituye una novedad y una innovación respecto de la regulación española que sirvió de base para la regulación chilena ${ }^{2}$, ya que al momento de ingresar el proyecto de ley al Parlamento chileno, la legislación hispana expresamente excluía la posibilidad de sancionar en los casos de conflicto en la aplicación de la norma tributaria ${ }^{3}$.

Pese a que la doctrina nacional ha criticado esta infracción, al considerar que no es un ilícito que tenga parangón en el mundo ${ }^{4}$, si se examinan las legislaciones comparadas es posible constatar que esa afirmación no es correcta, ya que actualmente la sanción al asesor fiscal se encuentra presente en más de un ordenamiento jurídico 5 .

En este contexto, la legislación chilena positiviza, mediante el ilícito del artículo 100 bis del Código Tributario, los postulados de la OCDE contenidos en su Plan Base Erosion and Profit Shifting (BEPS).

En efecto, si bien es cierto las acciones adoptadas en el marco de las BEPS no se refieren directamente a la inclusión en los ordenamientos jurídicos de cláusulas generales antielusión, ni a una sanción asociada a las mismas, estas directrices recogen ciertas estrategias de lucha contra la elusión fiscal consagradas en los ordenamientos jurídicos de Derecho comparado, que tienen el carácter de respuesta, disuasivo, y de detección. Así, las estrategias de respuesta no solo reprimen la elusión, sino que además influyen en comportamientos futuros del contribuyente, para disuadir aquellos que se consideran inaceptables. De las más pertinentes, las BEPS mencionan a "las normas o doctrinas generales de lucha contra la elusión fiscal, que limitan o rechazan la aplicabilidad de ventajas tributarias indebidas, por ejemplo, en situaciones en las que las operaciones carecen de contenido económico o de cualquier otra finalidad que no sea la meramente tributaria"6. De otra parte, las estrategias disuasivas buscan que los contribuyentes se desistan de implementar planificaciones fiscales agresivas, y entre ellas está la sanción

${ }^{2}$ El abuso de las formas jurídicas tiene su fuente en el conflicto en la aplicación de la norma tributaria consagrada en el artículo 15 de la Ley General Tributaria española; en el caso de la simulación, su similitud con la figura española del artículo 16 de la Ley General Tributaria es evidente. Véanse UgaLde Prieto, Rodrigo, 2018, p. 29 y MAgASICH, 2016, pp. 40, 490. En contra, SAFFie, quien ve en estas normas una inspiración en la legislación de Australia y Reino Unido. Historia de la Ley No 20.899, p. 105.

${ }^{3}$ De igual modo, la Ley 34/2015, de 21 de septiembre, modificó la Ley General Tributaria, eliminando la prohibición expresa de aplicar una sanción administrativa que rezaba el artículo 15.3 e incluyó un injusto administrativo en el artículo 206 bis del mismo cuerpo legal, que sanciona al contribuyente cuya planificación tributaria verifica los presupuestos aplicativos de la cláusula general antielusión.

${ }^{4}$ García y Álvarez, 2014, pp. 64, 66 y Ugalde, 2018, pp. 355 y ss.

${ }^{5}$ Entre otras, la sanción al promotor fiscal de tax exploitation schemes en Australia, regulada en la Sección 290-60 de la Tax Administration Act; la sanción de la Sección 141EB de la Tax Administration Act en Nueva Zelanda, y la sanción a los enablers que faciliten el uso de acuerdos elusivos de la Schedule 16 de la Finance ( $N^{\circ}$ 2) Act 2017. Todos los ordenamientos jurídicos mencionados contemplan además una sanción fiscal al contribuyente.

${ }^{6}$ OCDE, 2013, p. 45. 
de los promotores de estas planificaciones ${ }^{7}$, con las que se ataca la elusión desde lo que considera su origen ${ }^{8}$.

Basta con examinar la historia de la Ley $\mathrm{N}^{\circ} 20.780$, para concluir que la influencia de las BEPS es patente, pues se alude a ellas ya en el mensaje presidencial, que señala que Chile, con la introducción de la normativa general antielusión, se adaptaría a los estándares de lucha contra la evasión y elusión del proyecto BEPS, al rechazar las ventajas fiscales obtenidas por medio de "planificaciones elusivas y sancionar a los contribuyentes y asesores tributarios que hayan participado en su diseño" 9 . Avanzada la tramitación de este proyecto de ley, el entonces Ministro de Hacienda expresó la necesidad de incluir este tipo de normas, lo que en el plano internacional era impulsado por las BEPS y el G8, a lo que debía sumarse la Recomendación de la Comisión Europea a sus países miembros. Por lo demás, se señaló que comparativamente Alemania, Australia, Brasil, Canadá, Corea del Sur, España, Estados Unidos, Francia, Holanda y Reino Unido incluían este tipo de disposiciones en su legislación ${ }^{10}$.

Esta idea fue reiterada durante la tramitación de la Ley No 20.899, de 2016, pues el Director del Servicio de Impuestos Internos ${ }^{11}$ expresó que la incorporación de la norma general antielusión en el ordenamiento tributario chileno obedeció a la ejecución del compromiso adoptado por el país de "cumplir el estándar internacional sobre Erosión de la Base Imponible y Traslado de Beneficios (BEPS), que incluye precisamente medidas y normas antielusivas para enfrentar el comportamiento tributario agresivo y desleal" 12 .

Desde que Chile es parte de la OCDE ha alineado su normativa a los postulados de este organismo internacional. Por tanto, no es de extrañar la inclusión de esta sanción en el ordenamiento jurídico, pues su complejidad obliga al contribuyente a recurrir a asesoría experta para minorar la obligación tributaria o evitar realizar el hecho imponible u ocultarlo ${ }^{13}$. Asimismo, el asesor puede lograr tal efecto tributario respetando el ordenamiento jurídico o vulnerándolo ${ }^{14}$. De esta forma, si se regula un régimen sancionador aplicable al asesor fiscal, se consigue que mediante el temor al castigo si se

${ }^{7}$ OCDE, 2013, p. 44. De hecho, el tema ya había sido abordado en la Tercera Reunión del Foro OCDE sobre Administración Tributaria. En la declaración final acordada se propuso iniciar nuevas acciones, dentro de las que estaban analizar el papel de estos intermediarios fiscales en relación con el incumplimiento y promoción de planes de mitigación tributaria inaceptables. Declaración Final de Seúl, 2006, p. 6.

${ }^{8}$ Comparten esta apreciación en orden a que la infracción pretende atacar y acabar con la elusión tributaria desde lo que consideran es su origen, GARCía y Álvarez, 2014, pp. 65 y s.

${ }^{9}$ Historia de la Ley $\mathrm{N}^{\circ} 20.780$, p. 18.

${ }^{10}$ Historia de la Ley $\mathrm{N}^{\circ} 20.780$, pp. 1390 y s.

${ }^{11}$ En adelante SII.

${ }^{12}$ Historia de la Ley $\mathrm{N}^{\circ} 20.899$, p. 191.

13 Véanse Pont, 2003, p. 87 y VAN WeEzel, 2007, pp. 63 y s.

${ }^{14}$ En España, respecto de la simulación y del fraude a la ley (primera norma general antielusión de la legislación), se ha señalado que la intervención del asesor fiscal es casi obligatoria, pues lo normal será que el contribuyente carezca de la capacidad y conocimientos necesarios para adecuar la operación económica que pretende realizar a la alternativa fiscalmente menos gravosa. SÁNCHEZ, 2007, p. 292. En Chile es contrario a esta postura, Boetsch, 2016, p. 101. 
contraviene la normativa, esta se cumpla, con lo que los costos del control se desplazan del Estado a los asesores fiscales ${ }^{15}$.

\section{El ABUSO DE LAS FORMAS JURÍdiCAS Y LA SIMULACIÓN EN EL Derecho Tributario Chileno}

El contribuyente es libre de planificar su tributación de la forma que estime más pertinente. Sin embargo, según el grado de respeto del ordenamiento jurídico dicha planificación podrá ser catalogada como economía de opción, abuso o simulación ${ }^{16}$.

Tras la entrada en vigor del artículo $4^{\circ}$ ter del Código Tributario, que regula el abuso de las formas jurídicas, la legislación chilena cuenta por primera vez con una norma general antielusión ${ }^{17}$, que permite con carácter general señalar que las planificaciones que verifiquen sus presupuestos son elusivas $y$, consecuentemente, no resultan aceptadas por el Derecho tributario ${ }^{18}$. Esto es, permite desconocer los efectos tributarios de actos jurídicos válidos desde la perspectiva del Derecho común ${ }^{19}$.

El abuso presenta un presupuesto genérico de procedencia, consistente en que "se evite total o parcialmente la realización del hecho gravado, o se disminuya la base imponible o la obligación tributaria, o se postergue o difiera el nacimiento de dicha obligación”. Por tanto, para el legislador, no solo es elusión la no verificación del hecho gravado, sino también otras conductas en donde la actuación del contribuyente sí realizó el presupuesto del hecho imponible. De esta forma, el abuso se aleja de la concepción clásica de elusión ${ }^{20}$. Si concurre el presupuesto genérico, para aplicar la figura del abuso es necesario que este se alcance "mediante actos o negocios jurídicos que, individualmente considerados o en su conjunto, no produzcan resultados o efectos jurídicos o económicos relevantes para el contribuyente o un tercero, que sean distintos de los meramente tributarios", lo que en la doctrina nacional ha sido interpretado como una exigencia de business purpose test. Si concurren ambas exigencias, el efecto jurídico será que "se exigirá la obligación tributaria que emana de los hechos imponibles establecidos en la ley”.

Pese a que la legislación no exige que se verifique un test de artificialidad de los actos jurídicos, y por tanto, podría parecer que se aleja de la figura española, lo cierto es que este se encuentra implícito en las exigencias legales, pues de otro modo no se podría identificar nítidamente el deslinde con la economía de opción, regulada en el inciso $2^{\circ}$ de la norma y que corresponde a una planificación cuyos efectos son aceptados

\footnotetext{
15 BlázQuez, 2003, p. 38.

${ }^{16}$ Véase Alonso, 2006, p. 3038.

${ }^{17}$ Con anterioridad se contemplaban normas de carácter especial.

18 Véase García, 2004, p. 259.

19 Navarro, 2018, p. 188.

${ }^{20}$ Que, en concepto de Hensel, 2005, p. 230, nota 164, evita que surja el crédito fiscal, bordeando
} el hecho gravado. 
tributariamente. Por tanto, el juez al determinar la aplicación del abuso ponderará, implícitamente, que existe artificialidad en las formas utilizadas ${ }^{21}$.

Por su parte, la simulación, regulada en el artículo $4^{\circ}$ quater del Código Tributario, tiene una naturaleza jurídica evasiva ${ }^{22}$, pese a que el legislador la equipara a elusión. Lo propio de la evasión es que se esté ante un "incumplimiento (culpable) de un crédito nacido y válido, en virtud de la realización del presupuesto de hecho" ${ }^{23}$. La simulación, ya se contemplaba en la legislación tributaria, a propósito de los delitos tributarios ${ }^{24}$, pero, en la actualidad, se especifican sus presupuestos y su efecto en sede de cobro de impuestos. La norma dispone que cuando los actos jurídicos "disimulen la configuración del hecho gravado del impuesto o la naturaleza de los elementos constitutivos de la obligación tributaria, o su verdadero monto o data de nacimiento", el efecto será que "los impuestos se aplicarán a los hechos efectivamente realizados por las partes".

En el abuso existe una violación indirecta del ordenamiento jurídico, pues mediante formas jurídicas artificiales se respeta la letra de la ley, pero se vulnera su espíritu. En la simulación, se vulnera el ordenamiento, pues el hecho gravado se verifica, pero el contribuyente oculta al SII el hecho gravado, sus elementos, su monto o fecha. En este contexto normativo se inserta el ilícito del artículo 100 bis del Código Tributario.

\section{EL COMPLIANCE EN SEDE ADMINISTRATIVA SANCIONADORA: A PROPÓSITO DE LA SANCIÓN AL ASESOR EN SUPUESTOS DE ABUSO O SIMULACIÓN}

El sujeto activo del injusto regulado en el artículo 100 bis del Código Tributario es la persona natural o jurídica que ha diseñado o planificado uno o más actos jurídicos relacionados entre sí, que luego son declarados abusivos o simulados por un tribunal. Su sanción corresponde a una multa que asciende hasta el 100\% de los impuestos eludidos, con un tope $e^{25}$, ya que su importe no puede sobrepasar las 100 unidades tributarias anuales.

${ }^{21}$ Esto explica que las Directivas Europeas 2015/121, de 27 de enero de 2015 y 2016/1164, de 12 de julio de 2016, ambas del Consejo, no contemplen la artificialidad dentro de los presupuestos de la cláusula general antielusión.

22 YÁÑEZ, 2014, p. 245.

${ }^{23}$ Hensel, 2005, p. 230, nota 164.

${ }^{24}$ Vergara, 2016b, p. 356.

${ }^{25}$ El proyecto de ley de modernización de la legislación tributaria pretende incluir un segundo tope a la multa si existe reiteración. La disposición propone que "la multa no podrá superar las 250 unidades tributarias anuales, considerando el número de casos, cuantía de todos los impuestos eludidos y las circunstancias modificatorias de responsabilidad descritas en los artículos 110, 111 y 112 ”. Véase el número 38 , letra b del artículo $1^{\circ}$ del proyecto. El texto propuesto no establece un límite temporal para considerar la reiteración, ni asegura que se aplique solo en caso de una misma planificación tributaria da origen a más de un juicio y, por tanto, a más de una sanción. Ello, en atención a que la conducta típica a diseñar implica la confección de un modelo de ingeniería tributaria que, con pequeños ajustes, puede ser implementada por un sinnúmero de contribuyentes. 
El texto del artículo 100 bis contemplado en el proyecto de la Ley $\mathrm{N}^{\circ} 20.780$ enviado por el gobierno al Congreso que no establecía este tope. Ello generó enérgicas críticas durante la tramitación, por lo que se incluyó esta limitación mediante la indicación presidencial de 14 de abril de $2014^{26}$. La doctrina ve este límite máximo a la cuantía de la multa como un avance; de igual modo, expresa que puede crear una diferencia de compleja solución, pues los montos de ahorro impositivo que generan este tipo de operaciones son muy elevados, como también lo son los honorarios de los asesores, de forma tal que la amenaza de una sanción acotada puede hacer perder todo el efecto disuasorio pretendido ${ }^{27}$.

En materia de responsabilidad de la persona jurídica, la norma pareciera remitir directamente a la estructura del compliance penal contemplada en la Ley $\mathrm{N}^{\circ} 20.393$, de $2009^{28}$. Lo anterior, no es sino la concretización de lo que se ha señalado debiera ser el modelo de responsabilidad administrativa de la persona jurídica: un sistema en el que esta se pueda eximir de responsabilidad si demuestra "haber desarrollado seria y consistentemente un sistema adecuado de prevención de actuaciones ilícitas en el seno de la organización empresarial, sistema que si bien pudo haber fracasado en el caso en cuestión [...], permite ver dicho fracaso como un evento excepcional que no pone en duda la seriedad de los esfuerzos de prevención de la empresa” 29.

A continuación se efectuará un análisis dogmático de la infracción establecida en el artículo 100 bis del Código Tributario, resaltando aquellos elementos que resultan propios del compliance penal, regulado en la Ley $\mathrm{N}^{\circ} 20.393$.

\section{El sujeto activo del ilícito y el responsable de la sanción}

Es fundamental señalar que la persona que puede cometer esta infracción no es otra que el asesor tributario, pues entre las funciones que desarrolla se encuentra el diseño o planificación de un esquema que permita el ahorro tributario de su cliente. En efecto, se ha señalado que el asesor tributario corresponde a "un profesional que desarrolla una labor de asistencia técnica y de orientación a su cliente -con o sin su representación-, en el ejercicio de sus derechos y en el cumplimiento de sus deberes materiales y formales de contenido tributario ante la Hacienda Pública, planificando, normalmente, la fiscalidad del obligado tributario" 30 . Esta asesoría puede ser prestada directamente por una persona natural, o bien por una persona jurídica que encargará la labor a profesionales específicos.

${ }^{26}$ Historia de la Ley $\mathrm{N}^{\circ} 20.780$, p. 520.

27 AvilÉs, 2014, p. 250.

${ }^{28}$ El término compliance deriva de la expresión anglosajona to comply with, que a su turno significa "cumplir" o "cumplir con”. En sentido amplio, apunta a la observancia de parámetros legales, de carácter ético e incluso de política empresarial; en sentido restringido, se refiere a la actuación en consonancia con la normativa vigente. GARCía, 2017, p. 5. En el ámbito penal, con esta expresión se hace referencia a la normativa que permite atribuir responsabilidad a la persona jurídica.

${ }^{29}$ HernÁndeZ, 2018, p. 429.

30 Pont, 2003, p. 73. Véase también UGalde, 2018, p. 361. 
El SII, sin embargo, parece interpretar más ampliamente el sujeto activo de este injusto e incluye al contribuyente, pues instruye que el "sujeto sancionado puede ser tanto el contribuyente como cualquier otra persona, natural o jurídica, que haya diseñado o planificado los actos de que se trata” ${ }^{31}$. No se comparte la apreciación del SII, por distintas consideraciones que siguen.

Si se examina la historia de la ley es posible constatar que lo que busca esta norma es ser fiel reflejo de los postulados BEPS, los que a su vez pretenden erradicar la elusión fiscal desde lo que se considera su origen, por medio de la intervención de un asesor tributario; asimismo, es importante precisar que el mero origen de la disposición no sería un argumento valedero si luego la norma que contiene el ilícito se escapa de las directrices BEPS. Si se revisa el ilícito del artículo 100 bis del Código Tributario y el estatuto general chileno del abuso de las formas jurídicas y de la simulación, es claro que la disposición parte de la base de que el sujeto activo es un tercero distinto del contribuyente ${ }^{32}$, de ahí que se explique que el artículo $4^{\circ}$ quinquies del Código Tributario establezca la necesidad de citar al asesor en el proceso administrativo previo al requerimiento ante los Tribunales Tributarios y Aduaneros que lleva a cabo el SII ${ }^{33}$. Finalmente, si se examina la experiencia de las legislaciones que sancionan la elusión fiscal -muchas de estas fueron citadas expresamente durante la tramitación de las Leyes $\mathrm{N}^{\text {os }} 20.780$ y 20.899 - es posible encontrar sanciones que se aplican a dos sujetos distintos: una directamente al contribuyente y otra al asesor tributario. De ello se sigue que el legislador, de haber querido sancionar al contribuyente, lo habría dejado expresamente establecido. Sin embargo, ello no aconteció, pues los verbos rectores de la conducta ilícita dan cuenta de una acción que tiene lugar respecto de otro, como se verá más adelante ${ }^{34}$.

En definitiva, debido a que el contribuyente no es el sujeto activo de la infracción en comentario, se considera que si el SII persiguiese su responsabilidad administrativa y el tribunal acogiese tal pretensión, se estaría vulnerando el principio de tipicidad que rige en materia sancionadora. También, la problemática se daría a nivel interpretativo, por lo que se estima sería improcedente el requerimiento de inaplicabilidad por inconstitucionalidad ante el Tribunal Constitucional.

Por otra parte, es primordial expresar que de manera clara el artículo 100 bis en comentario introduce la estructura del compliance penal en materia tributaria, pues vincula la sanción de la persona jurídica al incumplimiento de deberes de dirección y supervisión que recaen en los directores o representantes legales, tal vez introduciendo una primera norma que puede ser la antesala de la sanción penal de la persona jurídica en caso de delitos tributarios. Ello es relevante, pues pese a las continuas modificaciones

\footnotetext{
${ }^{31}$ Circular $N^{\circ}$ 65, de 2015, p. 28. También Ugalde, 2018, p. 359.

32 En este sentido el ministro de Hacienda, quien señaló que la disposición en comento sanciona a los asesores de una planificación elusiva. Historia de la Ley $\mathrm{N}^{\circ} 20.780$, p. 529.

33 Vergara, 2016b, p. 385.

${ }^{34}$ Quizás la interpretación del ente fiscalizador explique que el proyecto de modernización de legislación tributaria expresamente exceptúe al contribuyente como sujeto activo de la infracción. Véase el numeral 38, letra a) de artículo $1^{\circ}$ del proyecto de ley.
} 
que ha sufrido el catálogo de delitos que pueden dar lugar a la responsabilidad penal de la persona jurídica de la Ley $\mathrm{N}^{\circ}$ 20.393, aún no contempla dentro de su listado a los delitos tributarios, con lo que en materia penal tributaria solo es posible atribuir responsabilidad a las personas naturales ${ }^{35}$.

Ahora bien, más que regular la forma de hacer efectiva la responsabilidad penal de la persona jurídica, la disposición pareciera reenfocar la responsabilidad en las personas naturales que incumplieron su deber de dirección y supervisión, pues ellos responderán pecuniariamente de la comisión de la infracción ${ }^{36}$.

En efecto, si el director o representante legal cumplió con sus deberes y de todos modos se diseñó o planificó un esquema abusivo o simulado, pareciera ser que pese a que se cometió una infracción, nadie responderá pecuniariamente, pues no existe base legal para hacer responder a la persona natural (trabajador) que materialmente diseñó o planificó los actos jurídicos ${ }^{37}$. Tal interpretación cobra mayor vigor si se examina la regulación de la responsabilidad de la persona jurídica en el texto original inciso $2^{\circ}$ del artículo 100 bis del Código Tributario, que prescribía que "[p]ara estos efectos, en caso que la infracción haya sido cometida por una persona jurídica, la sanción señalada podrá, además, ser aplicada a sus directores, o representantes legales”.

De la lectura de la disposición resulta palmario que la norma distinguía entre el sujeto activo de la infracción, que en este caso era la persona jurídica, y quienes eran responsables de solventar la sanción, pues la misma podía ser aplicada además de la persona jurídica a los directores o representantes legales. A mayor abundamiento, si se la compara con la actual redacción es evidente que se precisó en qué casos serían responsables los directores o representantes legales, porque se exige que hayan infringido sus deberes de dirección y supervisión y se eliminó toda referencia a que la sanción podrá aplicarse a estas personas además de la persona jurídica. En definitiva, el inciso $2^{\circ}$ del artículo 100 bis del Código Tributario no atribuye responsabilidad a la persona jurídica, de lo que se sigue que sin perjuicio de que la norma considere en el inciso $1^{\circ}$ como sujeto activo de la infracción tanto a la persona jurídica como a la persona natural, en los hechos, ello no deja de ser una declaración de principios $^{38}$ y será siempre una persona natural la que responda, con la salvedad de que probablemente existirá una importante

${ }^{35}$ De este modo, por vía indirecta pueden resultar aplicables las normas del compliance penal a la persona jurídica en sede tributaria, a propósito del delito de lavado de activos de la Ley $\mathrm{N}^{\circ} 19.913$. Tal normativa, en su artículo 27, sanciona al que de cualquier forma oculte o disimule el origen ilícito de determinados bienes, a sabiendas de que provienen, directa o indirectamente, de la perpetración de hechos constitutivos de ciertos delitos, dentro de estos se encuentra el ilícito del artículo 97 número 4 inciso $3^{\circ}$ del Código Tributario.

36 Así, por lo demás, parece entenderlo el SII en la Circular $N^{\circ} 65$, de 2015, p. 28, agregando que si se acredita fehacientemente que el respectivo director o representante legal se opuso a la propuesta, no responderá de la sanción.

${ }^{37}$ En el mismo sentido, Vergara, 2016a, p. 253.

${ }^{38}$ Se elimina así el esquema de doble punición propuesto en el proyecto de ley, cuya característica radica en que se sanciona a las personas jurídicas juntamente con los órganos o personas naturales que por ellas actúan. Para mayores detalles de este tipo de responsabilidad, véase al respecto López, 2009, pp. 105 y ss. 
diferencia entre la solvencia patrimonial que tendrá la persona natural en comparación con la que detenta la persona jurídica ${ }^{39}$.

El proyecto de modernización de la legislación tributaria incorpora un agregado al artículo 98 del Código Tributario, según este, en el caso de las personas jurídicas, habrá ciertas personas que serán solidariamente responsables ${ }^{40}$, la que debe ser interpretada en el sentido de que el obligado es el contribuyente y que las personas que el proyecto enumera son solidariamente responsables. De aprobarse esta norma, pudiera interpretarse la sanción establecida en el artículo 100 bis del Código Tributario en el sentido de que cuando la persona jurídica es el sujeto activo, la sanción recae sobre su patrimonio, pero con la particularidad de que los directores o representantes legales son solidariamente responsables cuando hayan incumplido sus deberes.

No es esta, sin embargo, la interpretación que se sigue. En primer lugar, debido a que la mentada enmienda legal no contempla al representante legal dentro de las personas que pueden responder solidariamente en caso de infracción de la persona jurídica, con lo que sería difícil sostener una interpretación como la señalada previamente, pues implicaría una aplicación analógica in malam partem de una norma sancionadora. Y, en segundo lugar, ya que con esta modificación la persona jurídica perdería cualquier tipo de incentivo a organizarse de una forma que le permitiera controlar la labor de la asesoría tributaria que presta, pues siempre que se cometiera la infracción ella sería responsable ${ }^{41}$.

\section{Las conductas sancionadas por el ilícito contemplado en el artículo 100 bis del Código Tributario}

La infracción aplicable al asesor fiscal cobra sentido desde el momento en que el legislador considera que este facilita al contribuyente un bien escaso ${ }^{42}$, ya que este tiene un conocimiento acabado de la legislación, en particular de la tributaria, de contabilidad, de los criterios interpretativos del SII y del estado de la jurisprudencia. Tal expertise, en algunos casos, lo habilita para que su cliente obtenga un ahorro tributario, mediante vías no admitidas por el Derecho tributario chileno: mediante abuso o simulación, de ahí que se le sancione.

Lo que no debe perderse de vista es que el asesor mostrará las distintas opciones a las que puede adoptar su cliente, indicando los riesgos asociados y el ahorro impositivo

39 Véase López, 2009, pp. 99 y s.

${ }^{40}$ El número 36 del artículo $1^{\circ}$ del proyecto de ley agrega la siguiente frase al artículo 98 del Código Tributario: "[e]l gerente general, administrador o quienes cumplan las tareas de estos, y los socios a quienes corresponda dicho cumplimiento, pero solo en el caso que los mencionados anteriormente hayan incurrido personalmente en las infracciones".

41 Véase Hernández, 2018, pp. 432 y s.

42 En la nomenclatura de Gimbernat, 1966, pp. 151 y ss. Si bien es cierto el citado autor rebautizó su teoría años después por la de actos no neutrales. El Mismo, 2013, pp. 70 y ss., el núcleo de lo que afirmó en su primitivo trabajo es perfectamente aplicable a la infracción que se examina. 
derivado de cada una de ellas. Pero, en definitiva, está en manos del contribuyente el hecho de que se ejecuten planificaciones fiscales agresivas ${ }^{43}$.

\section{2.a) La conducta genérica: "diseñar" o "planificar"}

El artículo 100 bis del Código Tributario sanciona la comisión por parte del asesor tributario de dos conductas típicas, de carácter alternativo, consistentes en diseñar y planificar actos, contratos o negocios constitutivos de abuso o simulación. Si bien diseñar y planificar pudieran considerarse como sinónimos ${ }^{44}$, es necesario establecer la diferenciación, ya que el legislador en este punto no ha querido ser redundante. Es así como el diseño ${ }^{45}$ está pensado como una planificación en masa que el asesor fiscal solo adapta a las necesidades particulares del contribuyente; en cambio, la planificación ${ }^{46}$ supone la elaboración de un entramado negocial, hecho a la medida del contribuyente.

Es pertinente apuntar que no se contempla como conducta típica el aprovechamiento o las ventajas derivadas de la planificación o diseño ${ }^{47}$. Ello refuerza la hipótesis de que el contribuyente no es el sujeto activo de esta infracción, ya que sería quien podría aprovecharse del abuso y la simulación, y demuestra que las conductas sancionadas en el artículo 97 número 4 del Código Tributario difieren de la tipificada en el injusto en análisis ${ }^{48}$.

El ilícito administrativo en comentario sanciona expresamente a un partícipe, porque el asesor fiscal -si bien realiza la conducta típica descrita en el artículo 100 bis del Código Tributario-, es un colaborador y, por tanto, un tercero en la actuación desplegada por el contribuyente. La disposición no exige que el asesor fiscal, además de planificar o diseñar, implemente la planificación fiscal ${ }^{49}$. Pese a ello, es necesario que

43 Véase OCDE, 2008, p. 5.

${ }^{44}$ Como hace el SII, en la Circular No 65, de 2015, p. 28.

45 Según la RAE, diseñar es hacer un diseño. A su turno, diseño, dentro de sus múltiples acepciones alude a una "concepción original de un objeto u obra destinado a la producción en serie". Esta expresión recuerda lo que para la OCDE son los productos fiscales normalizados, cuya característica es la facilidad de réplica, por lo que las describe como estructuras empaquetadas o de enchufar y usar, ya que el cliente compra un producto fiscal que requiere poca o ninguna modificación para adaptarlas a sus circunstancias. OCDE, 2016, p. 43.

46 Recurriendo nuevamente a la RAE, planificar es someter a planificación, y por planificación se alude a un "plan general, metódicamente organizado y frecuentemente de gran amplitud, para obtener un objetivo determinado, tal como el desarrollo armónico de una ciudad, el desarrollo económico, la investigación científica, el funcionamiento de una industria, etc.". En el caso de la planificación desarrollada por el asesor tributario, el objetivo buscado será eliminar o reducir la tributación del cliente, pero alejándose de la legítima economía de opción, cayendo en los presupuestos de hecho del abuso o de la simulación.

${ }^{47}$ Massone, 2016, p. 685, a pesar de que el autor estima que ello puede ser incluso más grave.

${ }^{48}$ No se abordará esta problemática, pues ella excede con creces las pretensiones de este trabajo.

${ }^{49}$ El texto original del artículo 100 bis del Código Tributario contemplado en el proyecto de la Ley $\mathrm{N}^{\circ} 20.780$ incluía una tercera conducta sancionada consistente en implementar estos actos, contratos o negocios. Las críticas no se hicieron esperar, y la referencia se eliminó. Lo objetado fue que era común que una persona, generalmente una auditora, realizara el diseño y otra efectuase la implementación, la que podía corresponder a "abogados o contadores que o no son especialistas y por lo tanto desconocen los alcances o efectos 
exista una declaración judicial que califique los actos como abusivos o simulados, por lo que la planificación tributaria ha de ser implementada, siendo indiferente para los efectos de la verificación de la infracción quien efectúe esa conducta.

\section{2.b) El compliance y las conductas exigidas a los directores o representantes legales}

La ley expresamente consigna como sujeto activo del ilícito del artículo 100 bis del Código Tributario a la persona jurídica, haciendo responsables de la sanción, en definitiva, a los directores o representantes legales que hayan incumplido ciertos deberes. Las sanciones administrativas atribuibles a las personas jurídicas persiguen, por definición, propósitos exclusivamente instrumentales, tendientes a servir como incentivo a cierto tipo de conductas ${ }^{50}$. En este caso concreto, lo que se persigue es evitar que el asesoramiento dado por los asesores tributarios permita al contribuyente vulnerar el ordenamiento jurídico, sea de manera directa o indirecta, según se esté ante un supuesto de simulación o de abuso.

En este contexto, se estima que el representante legal al que alude la norma no se refiere a aquel que consta en los registros del SII, de conformidad con el artículo $9^{\circ}$ del Código Tributario, sino que este debe identificarse conforme con los criterios propios de la legislación mercantil o civil $^{51}$, porque interesa determinar quién efectivamente omitió el cumplimiento de los deberes de dirección y supervisión. De otra parte, tampoco es sostenible afirmar que todos los directores o representantes legales de una persona jurídica deban siempre responder, pues solo serán responsables aquellas personas que tengan atribuidos poderes de dirección o supervisión, y ello dependerá de la concreta división de funciones asignada ${ }^{52}$. Para establecer la responsabilidad infraccional no basta la calidad jurídica que detente una persona, sino que, además, es relevante que esta tenga asignada la función de dirigir y supervisar la actividad de asesoramiento tributario a los contribuyentes $^{53}$ y que haya incumplido estos deberes.

Si se revisa la Historia de la Ley No 20.780, no surgen mayores luces acerca de qué ha de entenderse por los deberes de dirección y supervisión, referencia que fue incluida por medio de la indicación presidencial de 14 de abril de $2014^{54}$. El único antecedente que existe da cuenta de que en la Comisión de Hacienda de la Cámara de Diputados el Ministro de Hacienda explicó que la incorporación de esta referencia se efectuó para

de lo que están implementando, o siendo especialistas, no tienen un conocimiento global y pormenorizado del conjunto de la operación”. Aste, 2015, p. 11. También AvilÉs, 2014, p. 250.

${ }^{50}$ Hernández, 2018, p. 433.

51 En el mismo sentido Vergara, 2016a, p. 253.

52 Véanse Zornoza, 1992, pp. 197 y s. y Morales, 2013, p. 96.

53 La doctrina ha señalado la necesidad de que los directores o representantes legales "hayan tenido conocimiento efectivo de la operación que sus dependientes, respecto de quienes tenían poder de dirección, estaban planificando o diseñando". Boетsch, 2016, p. 150. No se comparte esta opinión, toda vez que lo relevante no es el conocimiento de la operación, sino la infracción del deber de dirección y supervisión.

${ }^{54}$ Historia de la Ley $\mathrm{N}^{\circ} 20.780$, p. 520. 
cumplir con los requerimientos de la Nueva Mayoría, con el fin de precisar que la sanción se aplicaría a estas personas solo si hubiesen infringido los deberes de dirección y supervisión ${ }^{55}$. Por lo demás, estos deberes tampoco aparecen definidos en la legislación tributaria y la interpretación de esta normativa efectuada por el SII los ha vinculado con deberes que emanan de los estatutos o de obligaciones y responsabilidades que se les han conferido a estas personas por el respectivo ente moral ${ }^{56}$.

Sin embargo, se estima que para dilucidar este punto, no se debe perder de vista la normativa que contempla la Ley $\mathrm{N}^{\circ} 20.393$, que regula la responsabilidad penal de la persona jurídica, normativa que terminó con el aforismo societas delinquere non postest en el Derecho penal chileno, en el caso de los delitos expresamente señalados ${ }^{57}$, estableciendo un sistema de atribución de responsabilidad a la persona jurídica ${ }^{58}$.

El modelo regulado por la Ley $\mathrm{N}^{\circ} 20.393$ establece un sistema mixto de imputación que combina el defecto de organización -que es el que permite que se cometa el ilícito en el interior de la persona jurídica-, desvinculado parcialmente del delito de la persona natural ${ }^{59}$. Esto es, la persona jurídica ha contribuido a la comisión del hecho al haberse organizado de un modo que favorece, o que no impide ni dificulta, la realización de este tipo de hechos. Lo que precisa es que se controle la comisión de ilícitos vía autorregulación forzada, es decir, imponiendo a las empresas el deber de organizarse y regularse de modo que se prevenga y detecte la comisión del injusto.

El modelo de atribución de responsabilidad penal de la Ley $\mathrm{N}^{\circ} 20.393$ se basa en la existencia de un hecho punible cometido por alguna de las personas que realicen actividades de administración en esta, o por personas naturales que estén bajo la dirección o supervisión de alguno de estos sujetos. Se requiere que la comisión de delito haya sido en interés o para el provecho de la persona jurídica y que haya habido incumplimiento por parte de la persona jurídica de su deber de dirección y supervisión, hecho que desencadena que se cometan delitos en su interior ${ }^{60}$.

${ }^{55}$ Historia de la Ley $\mathrm{N}^{0} 20.780$, p. 529.

56 Circular $\mathrm{N}^{\circ}$ 65, de 2015, pp. 28 y s., que cita como ejemplos los deberes de los artículos 551 del Código Civil, que prescribe que la dirección y administración de una asociación recaerá en un directorio; y 31 de la Ley $\mathrm{N}^{\circ}$ 18.046, de 1981, que determina que la administración de la sociedad anónima la ejerce el directorio, y que parece ir en línea con lo manifestado por Morales, 2013, p. 95, nota 7.

57 De conformidad con el artículo $1^{\circ}$ de la Ley $\mathrm{N}^{\circ} 20.393$, los delitos a los que se aplican estas disposiciones son: el financiamiento del terrorismo (artículo $8^{\circ}$ de la Ley $\mathrm{N}^{\circ} 18.314$, de 1984); el soborno o cohecho activo de empleado público nacional o funcionario público extranjero (artículos 250 y 251 bis del Código Penal); el lavado de activos (artículo 27 de la Ley No 19.913, de 2003); la receptación (artículo 456 bis A del Código Penal); los tipos penales de negociaciones incompatibles, de corrupción entre particulares, de apropiación indebida y de administración desleal (artículos 240, artículos 287 bis y ter, 470 número 1 y 470 número 11, respectivamente, todos del Código Penal). Y, finalmente, la contaminación y otras conductas relacionadas con ella (artículos 136, 139, 139 bis y 139 ter de la Ley No 18.892, de 1989).

${ }^{58}$ La persona jurídica responde por el ilícito cometido por una persona natural, no por el ente moral. De lo contrario, sería necesario dar respuesta a la pregunta acerca de cómo podría la persona jurídica cometer delito. Corcoy y Gómez, 2014, p. XIX.

${ }^{59}$ Bofill, 2011, p. 184.

${ }^{60}$ Véase el artículo $3^{\circ}$ de la Ley $N^{\circ} 20.393$. 
Se debe reconocer que existen importantes diferencias entre la forma de atribuir responsabilidad a la persona jurídica y la regulación de la responsabilidad en la sanción de los directores o representantes legales en el artículo 100 bis del Código Tributario. El estatuto regulado por la Ley $\mathrm{N}^{\circ} 20.393$ exige, por regla general, que una persona natural realice una conducta ilícita, esto es, que cometa un delito de aquellos establecidos en el artículo $1^{\circ}$ de la citada ley; además, requiere que la conducta ilícita haya redundado en un beneficio para la persona jurídica; las sanciones resultan aplicables a la persona jurídica, pues es ella la que soporta la imposición de la pena; es necesario que se hayan incumplido los deberes de dirección o supervisión, lo que tendrá lugar cuando, con anterioridad a la comisión del delito, la persona jurídica no hubiere adoptado e implementado modelos de organización, administración y supervisión para prevenir delitos $y$, finalmente, la pena aplicable no es solo una multa.

Pese a las diferencias anotadas, se estima que la referencia que efectúa el artículo 100 bis del Código Tributario al incumplimiento por parte de los directores o representantes legales de los deberes de dirección y supervisión, puede ser interpretada a la luz de las exigencias del inciso $3^{\circ}$ del artículo $3^{\circ}$ de la Ley $\mathrm{N}^{\circ} 20.393$. Se llega a la conclusión anterior por una razón de texto, y es que en ambas normativas se sanciona por la infracción de deberes de dirección y supervisión que tienen sentido dentro de un sistema de atribución de responsabilidad sancionatoria en sentido amplio a la persona jurídica. De otra parte, no se puede desconocer que el legislador ha sido más garantista con el sujeto activo en estos casos que en los restantes: exige que la comisión de la infracción y la responsabilidad que en ella le cabe a una persona determinada sea decretada por un tribunal (y no por el SII), y la sanción se anuda al incumplimiento de controles internos. Asimismo, la normativa en este punto se aleja de la regla establecida en el artículo 98 del Código Tributario, relativo a la responsabilidad en las sanciones pecuniarias por la comisión de ilícitos administrativos, en virtud de ello, la persona jurídica puede ser responsable de la comisión de infracciones tributarias sin que se establezcan mayores exigencias ${ }^{61}$. Finalmente, esta normativa pretende desincentivar la conducta sancionada, persiguiendo que se tomen los resguardos necesarios dentro de la organización para evitar que se incurra en la conducta sancionada: diseñada o planificada a consecuencia de un ineficiente control de la persona jurídica en la forma de prestar asesoría tributaria al cliente.

Todo ello hace pensar, desde un punto de vista sistemático, que el ilícito regulado en el artículo 100 bis del Código Tributario es sometido por el legislador a un estatuto particular que se aleja de las restantes infracciones tributarias. Y se estima que a esta conducta ilícita se le aplica un estatuto jurídico que queda a medio camino entre el propio de las infracciones y el correspondiente a los delitos tributarios, aunque estos no estén incluidos en el catálogo de delitos a los que se aplican las disposiciones de la Ley $\mathrm{N}^{0} 20.393$.

\footnotetext{
${ }^{61}$ Massone, 2010, p. 96.
} 
Es cierto que la Ley $\mathrm{N}^{\circ} 20.393$ no precisa en qué consisten estos deberes, pero sí señala cuándo se entiende que se cumple con los deberes de dirección y supervisión. Ello acontecerá cuando se hayan implementado compliance programs o programas de cumplimiento, esto es, un "conjunto de medidas adoptadas por la empresa para controlar dentro de lo exigible los peligros de infracción al ordenamiento jurídico que pueden derivar de su misma actividad" 62 . De ahí que se afirme que lo que se busca no es sancionar a la persona jurídica, sino promover una cultura ética empresarial ${ }^{63}$.

En relación con este asunto, podría caerse en la tentación no solo de interpretar los deberes de dirección y supervisión a la luz de la Ley N N $^{\circ} 2.393$, sino que incluso hacerle aplicable a las personas jurídicas la implementación de un programa de cumplimiento más allá de los casos de responsabilidad penal que regula la referida ley. Se considera, sin embargo, que los términos del artículo 100 bis del Código Tributario no permiten llegar tan lejos, y proceder en tal sentido implicaría hacer una aplicación analógica in malam partem de la legislación penal al ámbito administrativo sancionador. No obstante, contar con un protocolo de actuación que permita efectuar comprobaciones y revisiones a la asesoría jurídica prestada, puede servir como medio de control de la calidad de los servicios prestados, pero también del ajuste de estos a la legalidad vigente, con lo que puede atenuar o derechamente excluir la responsabilidad administrativa regulada en el artículo 100 bis en comento.

Desde un punto de vista semántico y, por tanto, aplicable no solo a la sociedad anónima ${ }^{64}$, dirección es la acción y efecto de dirigir, y en el contexto que se examina resulta aplicable la acepción de dirigir de la RAE, que indica que corresponde a "[g]obernar, regir, dar reglas para el manejo de una dependencia, empresa o pretensión”, por tanto, corresponde a las directrices que se dan en el desarrollo del negocio. Por su parte, supervisión es la acción y efecto de supervisar, la que a su vez alude a "[e]jercer la inspección superior en trabajos realizados por otros”, en el fondo, es el examen de alguien con autoridad de la forma cómo se desarrolla el trabajo propio de la persona jurídica ${ }^{65}$.

62 Artaza, 2013, p. 545.

${ }^{63}$ Ello es expresamente reconocido en España por la Circular N $N^{o} 1 / 2016$, de la Fiscalía General del Estado, pp. 39, 52, que pone el énfasis en que la empresa debe contar con un modelo para cumplir con la legalidad en general y, evidentemente, con la legalidad penal.

${ }^{64}$ Según dispone el artículo 41 de la Ley de Sociedades Anónimas, los directores deberán "emplear en el ejercicio de sus funciones el cuidado y diligencia que los hombres emplean ordinariamente en sus propios negocios y responderán solidariamente de los perjuicios causados a la sociedad y a los accionistas por sus actuaciones dolosas o culpables”.

${ }^{65}$ En España, la legislación contempla una regulación similar para atribuir responsabilidad a la persona jurídica y la Fiscalía General ha entendido que supervisión y vigilancia -este último término no utilizado en la norma penal chilena- enfatizan que ese control o fiscalización es externo y superior respecto de las tareas encomendadas o a cargo de otros. El sistema penal, en estos casos, considera que la infracción de estos deberes es lo que transfiere responsabilidad a la persona jurídica, pues, sin ella, la conducta del subordinado es irrelevante. Véase Circular No 1/2016, de la Fiscalía General del Estado, pp. 22, 24. De todos modos, a diferencia de la exigencia chilena, en España el incumplimiento de estos deberes ha de ser grave y debe valorarse atendidas las concretas circunstancias del caso. 
Como apunta Silva Sánchez, la supervisión supone la vigencia del principio de desconfianza en el actuar del otro, en virtud de ello, es necesario procurarse de información acerca de la forma en que el tercero gestiona su esfera de competencia. La dificultad está en la manera de fundamentar la vigencia de este principio de desconfianza, que conlleva un deber previo de obtener conocimiento de la forma cómo el subordinado gestiona su esfera de competencia, y uno posterior, de instar a que este corrija su actuación defectuosa en el seno de su competencia, evitando las consecuencias lesivas derivadas de aquella ${ }^{66}$. La hipótesis del autor es que dicho deber se fundaría en la "tendencia de quienes integran estas organizaciones a la desorganización progresiva, a orientarse únicamente al lucro, a generar pautas informales de conducta [...], a minusvalorar determinados riesgos" 67 .

La regulación de esta infracción pretende que las personas jurídicas que prestan asesoría en materia tributaria establezcan sistemas de control internos de la calidad de ese producto que se entrega al contribuyente, de forma que si no se puede eliminar de raíz el diseño o planificación de actos, contratos o negocios abusivos o simulados, al menos ellos se vean considerablemente reducidos. Lo relevante es que la persona jurídica alcance una cultura organizacional, al interior de la empresa que presta asesorías tributarias, según estos, en el cumplimiento de los encargos hechos por su cliente respete la letra y espíritu de la legislación tributaria, introduciendo los controles necesarios para velar por ello.

\section{El principio de culpabilidad y la estructura del compliance}

La solución legislativa tendiente a aplicar la estructura del compliance a la infracción del artículo 100 bis del Código Tributario puede servir para solucionar el problema apuntado por Hernández respecto de la imposibilidad de aplicar las exigencias de culpabilidad a la persona jurídica, tanto en sede penal como administrativa, por razones estructurales derivadas de la naturaleza de estas personas, que impiden imputarles algo que ellas hayan hecho. De ahí que atribuir responsabilidad a las personas jurídicas por medio de un sistema de compliance pueda resultar útil para evitar caer en un modelo de responsabilidad automática frente a la comisión de un ilícito ${ }^{68}$. En la infracción que se comenta las exigencias derivadas del principio de culpabilidad debieran tener aplicación respecto de la persona natural ${ }^{69}$, sea que ella haya cometido la infracción, sea que se trate del director o representante legal que ha incumplido sus deberes de dirección y supervisión.

Igualmente se considera necesario aclarar un punto vinculado directamente con el respeto al principio de culpabilidad, pues se podría sostener que no es admisible la sanción en los supuestos en que ha tenido aplicación el abuso o la simulación, pues

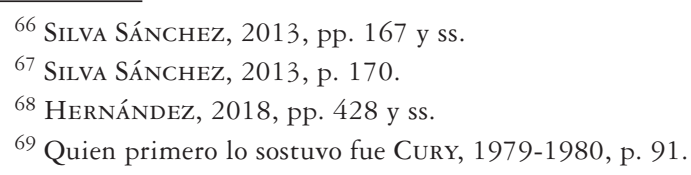


estas figuras, según disponen los artículo $4^{\circ}$ ter y $4^{\circ}$ quater del Código Tributario, se conciben en términos objetivos.

Al respecto, se estima que no es relevante la ausencia de ponderación del elemento subjetivo para aplicar tanto el abuso cuanto la simulación, pues lo esencial consiste en que el tipo administrativo respete las exigencias de culpabilidad aplicables según la doctrina clásica (y últimamente criticada) ${ }^{70}$ del Tribunal Constitucional que estima que en materia de sanción administrativa resultan aplicables los principios penales aplicados con matices ${ }^{71}$.

Si se examina el artículo 100 bis del Código Tributario no existe ningún elemento que permita afirmar que la sanción prescinde de la acreditación del elemento subjetivo. Es más, se requiere que el SII -que insta a la determinación de la comisión del hecho y de la participación en el mismo del presunto responsable- pruebe todos los elementos del injusto, pues la norma dispone que debe ser demostrado que el asesor fiscal efectuó el diseño o planificación de actos jurídicos declarados abusivos o simulados. Con lo que el ente fiscalizador deberá acreditar la culpabilidad del sujeto activo en los casos en que la comisión de la infracción sea realizada por una persona natural, y de los directores o representantes legales, cuando hayan incumplido los deberes de dirección y supervisión, y se esté ante un supuesto en el que la persona jurídica es el sujeto activo.

\section{CONClusiones}

La legislación tributaria chilena, siguiendo los postulados de la OCDE recogidos en el Study into the Role of the Tax Intermediaries y en el Plan BEPS, se ha puesto a la vanguardia de los sistemas jurídicos que sancionan administrativamente al asesor fiscal en los supuestos en que ha tenido aplicación una norma general antielusión, incorporando la infracción regulada en el artículo 100 bis del Código Tributario. La particularidad es que el injusto no solo sanciona el diseño o planificación de actos jurídicos declarados luego por un tribunal como abusivos, y por tanto elusivos, sino que también aquellos sindicados como simulados, y por tanto evasivos.

Al respecto, es claro que para el legislador chileno era necesario introducir una norma que inhibiera la implementación de planificaciones tributarias abusivas o simuladas, que redundan en un incumplimiento de las obligaciones tributarias por parte del contribuyente, desde lo que consideró su origen: la intervención del asesor fiscal y su aportación del bien escaso consistente en el conocimiento técnico para vulnerar la legislación impositiva, sea de manera directa, en el caso de la simulación, sea de manera indirecta, en los supuestos de abuso de las formas jurídicas.

\footnotetext{
${ }^{70}$ Por todos, Letelier, 2016, pp. 627 y ss.

${ }^{71}$ Por todas, sentencia del Tribunal Constitucional, Rol $N^{\circ} 244$, considerando $9^{\circ}$.
} 
En este contexto, el injusto del artículo 100 bis del Código Tributario sanciona a la persona natural o jurídica que haya diseñado o planificado uno o más actos jurídicos que hayan sido implementados y que, con posterioridad, sean declarados abusivos o simulados.

Las conductas típicas, de carácter alternativo, no son sinónimas, sino que apuntan a sancionar dos formas distintas de asesorar al contribuyente en la minoración de la obligación tributaria o en la evitación u ocultación de la realización del hecho gravado. En efecto, diseñar está pensado para una planificación tributaria en masa, en la que el asesor fiscal solo adapta a las necesidades particulares del contribuyente; en cambio, la planificación supone la elaboración de un entramado negocial, hecho a la medida del contribuyente.

La particularidad de la infracción analizada radica en el hecho de que introduce la estructura del compliance penal para hacer efectiva la responsabilidad administrativa de la persona jurídica, pese a que los delitos tributarios no son de aquellos contemplados dentro del catálogo de la Ley $\mathrm{N}^{\circ} 20.393$, que permite imputar responsabilidad penal al ente moral.

En efecto, cuando el sujeto activo de la infracción es la persona jurídica, el artículo 100 bis del Código Tributario señala que responderán de la sanción los directores o representantes legales que hayan incumplido sus deberes de dirección y supervisión.

De esta forma, la legislación chilena quiere impactar en la manera cómo se presta la asesoría tributaria, pues ha establecido un sistema que permite eximir de responsabilidad infraccional al asesor fiscal, cuando este es una persona jurídica, si se estructura de una forma tal que permita establecer los controles necesarios para evitar que el producto de su asesoría consista en un diseño o planificación de actos jurídicos abusivos o simulados. El sistema funcionará en la medida en que las sucesivas reformas que modifiquen el estatuto aplicable al abuso, a la simulación y a la sanción administrativa aplicable -con el fin de respetar en mejor medida la legalidad y la seguridad jurídica-, mantengan la estructura esencial de estas de forma tal que les permita cumplir con su finalidad: resguardar la correcta determinación de la obligación tributaria.

\section{BIBLIOGRAFÍA}

\section{Doctrina}

Alonso GonZÁlez, Luis Manuel, 2006: "Planificación fiscal y economía de opción”, Jurisprudencia Tributaria Aranzadi, volumen I, tomo XV.

Artaza Varela, Osvaldo, 2013: "Sistemas de prevención de delitos o programas de cumplimiento. Breve descripción de las reglas técnicas de gestión del riesgo empresarial y su utilidad en sede jurídico penal", Política Criminal, volumen 8, No 16.

Aste Mejías, Christian, 2015: Reforma tributaria. Comentada y explicada, Santiago: Legal Publishing. Avilés Hernández, Víctor Manuel, 2014: Legalidad tributaria y mecanismos anti elusión (2a edición), Santiago: Editorial Jurídica de Chile.

BLÁZQuEz Lidoy, Alejandro, 2003: "El régimen jurídico de la asesoría fiscal en Estados Unidos", Crónica Tributaria, $\mathrm{N}^{\circ} 109$. 
Boetsch Gillet, Cristián, 2016: La norma general anti elusión. Análisis desde la perspectiva del Derecho privado, Santiago: Ediciones UC.

Bofill Genzsch, Jorge, 2011: "Estructuras de imputación y prevención de delitos al interior de la persona jurídica", en Javier Wilenmann Von Bernath, Gobiernos corporativos. Aspectos esenciales de las reformas a su regulación, Santiago: Legal Publishing, pp. 175-195.

Corcoy Bidasolo, Mirentxu y Gómez Martín, Víctor, 2014: "Prólogo" de la obra Santiago Mir Puig, Mirentxu Corcoy Bidasolo y Víctor Gómez Martín (directores), Responsabilidad de la Empresa y Compliance. Programas de prevención, detección y reacción penal, Madrid: EDISOFER S.L. Libros jurídicos, pp. XIX-XXVI.

Cury Urzúa, Enrique, 1979-1980: "Algunas reflexiones sobre la relación entre penas penales y administrativas", Boletín de Investigaciones (Pontificia Universidad Católica de Chile), año VIVII, Nos 44-45.

DeClaración Final de Seúl, 2006: Tercera Reunión del Foro OCDE sobre Administración Tributaria. Seúl: 14-15 septiembre.

García Escobar, Jaime y Álvarez Maya, Carolina, 2014: “Análisis de algunos aspectos de una rabiosa reforma stalinista: la cláusula general antielusiva y la sanción que supone el artículo 100 bis del Código Tributario", Revista Actualidad Jurídica (Universidad del Desarrollo), No 30.

García Cavero, Percy, 2017: Criminal compliance, Lima: Instituto Pacífico.

García NovoA, César, 2004: La cláusula antielusiva en la nueva Ley General Tributaria, Madrid: Marcial Pons.

Gimbernat Ordeig, Enrique, 1966: Autor y cómplice en el derecho penal, Madrid: Universidad de Madrid, Facultad de Derecho, Sección de publicaciones e intercambio.

Gimbernat Ordeig, Enrique, 2013: "A vueltas con la imputación objetiva, la participación delictiva, la omisión impropia y el Derecho penal de la culpabilidad", Anuario de Derecho Penal y Ciencias Penales, volumen LXVI.

Hensel, Albert, 2005: Derecho tributario (trad. A. Báez, M. González-Cuellar y E. Ortiz), Madrid: Marcial Pons.

Hernández Basualto, Héctor, 2018: "Procedencia de una 'eximente o defensa de cumplimiento' de las personas jurídicas en el derecho administrativo sancionador chileno”, en Revista Chilena de Derecho, volumen 45, No 2 .

Historia de la Ley No 20.780. Disponible en http://www.bcn.cl/historiadelaley/nc/historia-dela-ley/4406/. [Fecha de consulta: 5 de diciembre de 2018].

Historia de la Ley No 20.899. Disponible en http://www.bcn.cl/historiadelaley/nc/historia-delaley/4829/. [Fecha de consulta: 5 de diciembre de 2018].

López López, Hugo, 2009: El principio de culpabilidad en materia de infracciones tributarias, Cizur Menor: Aranzadi.

Navarro Schiappacasse, María Pilar, 2018: "La evolución en la jurisprudencia de la Excma. Corte Suprema en la concepción de la elusión fiscal", Revista de Estudios Tributarios, No 20.

Magasich Airola, Álvaro Pablo, 2016: La derrotabilidad, fraude de ley y cláusula general antielusiva. Análisis desde el Derecho tributario español y chileno. Tesis para optar al grado de Doctor en Derecho y Ciencia Política. Universidad de Barcelona.

Massone Parodi, Pedro, 2010: Infracciones tributarias (2a edición), Santiago: Legal Publishing.

Massone Parodi, Pedro, 2016: Principios de derecho tributario (4 ${ }^{a}$ edición), Tomo I, Santiago: Legal Publishing.

Morales PeÑa, Roberto, 2013: "La imputación de responsabilidad penal a los órganos de las empresas, en relación con los presupuestos para que las acciones realizadas por personas individuales les puedan ser imputadas, cuando estas exceden en el ámbito propio del giro de la empresa", Revista Jurídica del Ministerio Público, $\mathrm{N}^{\circ} 55$. 
Letelier Wartenberg, Raúl, 2016: “Garantías penales y sanciones administrativas”, Política Criminal, volumen 12, $\mathrm{N}^{\circ} 24$.

OCDE, 2008: Study into the Role of Tax Intermediaries, Paris: Éditions OCDE.

OCDE, 2013: Lucha contra la erosión de la base imponible y el traslado de beneficios, Paris: Éditions OCDE.

OCDE, 2016: Exigir a los contribuyentes que revelen sus mecanismos de planificación fiscal agresiva. Acción 12 - Informe final 2015. Proyecto de la OCDE y del G-20 sobre la Erosión de la Base Imponible y el Traslado de Beneficios, Paris: Éditions OCDE.

Pont Clemente, Joan-Francesc, 2003: "Responsabilidad penal del asesor fiscal”, Revista Técnica Tributaria, $\mathrm{N}^{\circ} 63$.

SÁnchez Pedroche, José Andrés, 2007: Responsabilidad penal, civil y administrativa del asesor fiscal, Madrid: Ediciones CEF.

Silva SÁnchez, Jesús-María, 2013: Fundamentos del Derecho penal de la Empresa, Madrid: BdeF.

Ugalde PRIETo, Rodrigo, 2018: La elusión tributaria. El abuso de las formas jurídicas y la simulación, Santiago: Editorial Jurídica.

Van Weezel, Alex, 2007: Delitos tributarios, Santiago: Editorial Jurídica de Chile.

Vergara Quezada, Gonzalo, 2016a: "La despenalización de la simulación por la Ley N 20.780", Revista de Estudios Tributarios, $\mathrm{N}^{\circ} 16$.

Vergara Quezada, Gonzalo, 2016b: Norma antielusiva general. Sobre los fines en nuestras leyes tributarias, Santiago: Editorial Libromar.

Yáñez Villanueva, Felipe, 2014: “Análisis de la nueva cláusula general antielusiva”, Revista de Estudios Tributarios, $\mathrm{N}^{\circ} 11$.

Zornoza PÉrez, Juan, 1992: El sistema de infracciones y sanciones tributarias (Los principios constitucionales del derecho sancionador), Madrid: Civitas.

\section{Jurisprudencia judicial}

Tribunal Constitucional, sentencia de fecha 26 de agosto de 1996, Rol No 244-1996.

\section{Jurisprudencia administrativa}

Fiscalía General del Estado, Circular No 1/2016, de 22 de enero.

Servicio de Impuestos Internos, Circular No 65, de 23 de julio de 2015. 